\title{
Desenvolvimento tecnológico e inovação: um estudo comparativo sobre produtos biotecnológicos na agricultura
}

\author{
Maria Thereza Macedo Pedroso ${ }^{1}$ \\ Danilo Nolasco Cortes Marinho ${ }^{2}$ \\ Luiz Guilherme de Oliveira ${ }^{3}$
}

\begin{abstract}
Resumo
O Brasil, em termos de desenvolvimento tecnológico aplicado à agricultura, tem-se mostrado capaz de desenvolver produtos biotecnológicos poupadores de insumos, assim como os Estados Unidos. Ambos os países desenvolveram produtos transgênicos extremamente semelhantes em termos tecnológicos. No entanto, no que diz respeito à política de inovação agropecuária para esse tipo de produto, os dois casos apresentam diferenças cruciais. O artigo destina-se a apontar diversas características, comparando dois casos de desenvolvimento de produtos biotecnológicos poupadores de agroquímicos nos respectivos países, que podem explicar resultados diferentes para situações iniciais similares e exemplificar as fundamentais diferenças entre capacidade de pesquisa e inovação tecnológica.
\end{abstract}

Palavras chaves: Instituições. Transgênicos. Biotecnologia. Inovação tecnológica agropecuária.

\begin{abstract}
Brazil, in terms of technological development, has been able to develop biotechnological products that conserve inputs such as the United States. Both developed highly technologically similar transgenic products. However, with regard to the agricultural innovation policy for this type of product, the two countries present crucial differences. The article aims to point out several characteristics, comparing two cases of agrochemical-based biotechnological product development in the respective countries, which may explain different results for similar initial situations and to exemplify the fundamental differences between research capacity and technological innovation.
\end{abstract}

Keywords: Institutions. Transgenic. Biotechnology. Agricultural technological innovation.

\section{Introdução}

No Brasil, um dos esforços científicos mais espetaculares em biotecnologia resultou no desenvolvimento de uma variedade de feijão geneticamente modificado que, por ser resistente ao "vírus do mosaico dourado do feijoeiro", transmitido por um inseto-praga denominado "mosca branca", exige menor número de aplicação de inseticidas. Portanto,

\footnotetext{
${ }^{1}$ Doutora em Ciências Sociais. Pesquisadora da Embrapa Hortaliças. maria.pedroso@embrapa.br

${ }^{2}$ Doutor em Sociologia. Pós-Doutor pela Universiteit van Amsterdam. Professor do Departamento de Sociologia e do Centro de Américas da Universidade de Brasília (UnB). nolasco@unb.br

${ }^{3}$ Doutor em Política Científica e Tecnológica. Pós-Doutor pela Ecole des Hautes Études en Sciences Sociales (EHESS, França). Professor da Universidade de Brasília (UnB). Igoliveira@unb.br
} 
pode ser considerada mais sustentável, quando comparada com as variedades convencionais de feijão. Nos Estados Unidos, os mesmos tipos de esforços científicos resultaram no desenvolvimento de um tipo de mamão, o papaya geneticamente modificado que também evita o uso de inseticidas por ser resistente a um determinado vírus também transmitido por um inseto. São, portanto, dois produtos que exigem capacidade de pesquisa instalada, processos científicos, laboratoriais e experimentais similares e, em grande proporção, representam novas possibilidades produtivas. Adicionalmente, foram duas situações de pesquisa realizadas durante períodos de tempo similares. Ou seja, o tempo entre o início das duas pesquisas e o desenvolvimento completo dos dois produtos foi parecido. São aspectos, desta forma, que sugerem a possibilidade analítica de um estudo corporativo.

Contudo, existe uma diferença crucial entre os dois casos: nos Estados Unidos, o mamão papaya transgênico, assim que foi desenvolvido, passou a ser utilizado com rapidez em estabelecimentos rurais, muitos deles considerados familiares, ampliando a produção e a produtividade da fruta. Foram agilmente vencidos os trâmites burocráticos e os testes de validação e precaução, seguindo as normas legais existentes naquele país. Ou seja, o processo de inovação foi completo e realizado em tempo relativamente curto. No presente artigo, ao se analisar comparativamente o caso do feijão transgênico com o caso do mamão papaya demonstrou-se que, em ambos os países há capacidade instalada para desenvolver produtos agrícolas bastante sofisticados. No entanto, no Brasil, o feijão transgênico foi desenvolvido, mas não foi ainda disponibilizado para os agricultores até o presente momento. Portanto é um produto pronto, mas ainda não é uma inovação.

Sucintamente, é assim iluminado, nessa breve introdução, o contexto geral no qual se apresenta o tema desse artigo. Existem duas potências agrícolas cujas histórias de modernização agropecuária são similares sob diversos ângulos, inclusive porque um desses países (o Brasil) promoveu o seu processo de modernização agropecuária após o aprendizado acumulado pelo outro, os Estados Unidos. Inclusive, é provavelmente correto afirmar que, nos dois casos sob análise, o modus operandi científico, assim como o aparato laboratorial e experimental e os recursos humanos a ele associados são essencialmente similares. Mas as similaridades terminam aqui, pois as trajetórias dos respectivos processos de inovação experimentaram desenlaces bastante distintos nos respectivos contextos 
nacionais.

Dessa forma, em um subcampo específico, aqui intitulado de "produtos biotecnológicos poupadores de agroquímicos", os dois países vêm experimentando desenvolvimento científico expressivo, embora o Brasil ainda apresente menor avanço, em termos comparativos. Nos Estados Unidos, um desses produtos foi a criação do "mamão papaya transgênico", quando passou então a ser amplamente disponibilizado aos agricultores interessados. No Brasil, no mesmo subcampo de pesquisa, o "feijão transgênico" foi igualmente desenvolvido. Mas, não foi disponibilizado para os agricultores, pelos menos até outubro de 2017. O que significa que, apesar de as respectivas capacidades científicas serem similares, o processo de inovação tecnológico agropecuário encontrou diferenças substantivas.

As situações comparadas convergentes, mantidas todas as diferenças históricas, culturais ou econômicas, relacionadas com a atividade econômica denominada agricultura, são, sobretudo, as seguintes: ambos os países contam com (i) forte economia agrícola; (ii) essencialmente, o mesmo modelo tecnológico agrícola, pelo menos no tocante à rationale de seu funcionamento; (iii) semelhantes características do processo de desenvolvimento agrário recente (como, por exemplo, a concentração da produção, em valor); (iv) capacidades de pesquisa instaladas para desenvolver produtos biotecnológicos poupadores de insumos e, adicionalmente, ( $v$ ) necessidade de desenvolver tecnologias que tenham externalidades ambientais menores que as anteriores de mesmo tipo geral (ou seja, variedades transgênicas em substituição de variedades convencionais que proporcionem a redução do uso de agroquímicos).

\section{Fundamentação téorica: ciência, tecnologia e inovação}

Tecnologia não é a mera e imediata aplicação de conhecimento científico em uma situação concreta. De fato, a união da ciência com a tecnologia apenas surgiu quando o método científico foi desenvolvido e, assim, esta convergência, em termos históricos, é relativamente recente. A trajetória da tecnologia lato sensu se confunde com a história da humanidade, desde os primórdios dos agrupamentos humanos, quando os indivíduos passaram a desenvolver os seus primeiros instrumentos, na luta pela sobrevivência. Ainda 
hoje, muitas vezes, o conhecimento tecnológico precede o conhecimento científico e, dessa forma, a tecnologia passa a ser um repositório de conhecimento prático possível de ser escrutinizado pelos cientistas.

Por sua vez, o conhecimento científico ou, mais especificamente, o método científico, é construção social que foi se articulando logicamente nos últimos cinco séculos. Foi acionada com a descoberta dos "novos mundos", pois antes de 1492 o senso comum afirmava que todo conhecimento significativo já existia e era conhecido, não existindo, então, o conceito de progresso, pois o olhar dos indivíduos era dirigido ao passado, não ao futuro. Como Wootton (2015) demonstra em um livro inevitavelmente destinado a tornar-se um clássico, a sequência de transformações que gradualmente surgiu acabaria rompendo com o passado, modificando radicalmente a cultura e os comportamentos sociais. Em The Invention of Science (2015), o autor enfatiza:

[...] Qual é a relação entre a Revolução Científica e a Revolução Industrial, entre a revolução dos matemáticos e a revolução mecânica? O argumento, com o qual é aberto esse livro, que a Revolução Científica é o mais importante evento desde a Revolução Neolítica, depende de nossa resposta a essa questão. Porque se a Revolução Científica foi meramente um evento no mundo das ideias, sua importância é relativamente limitada, enquanto que ela se abriu o caminho para um novo controle sobre a natureza, então a Revolução Industrial pode ser entendida como apenas uma extensão da Revolução Científica, uma extensão dos procedimentos, linguagem e a cultura de uma nova ciência (WOOTTON, 2015, p. 476).

Em consequência, embora no período contemporâneo ocorra uma crescente convergência entre "ciência, o método científico e o conhecimento acumulado", de um lado, e "tecnologia" de outro lado, ainda existe uma relativa autonomia entre esses campos de ação humana. Tecnologia não é produto, pois uma tecnologia pode estar presente em vários tipos de produtos e um produto pode conter várias tecnologias. Os sistemas técnicos-físicos (maquinaria, equipamento, banco de dados, software, fábricas, etc.) são partes de uma dada tecnologia e a expressam em parte, mas não estritamente falando são a própria tecnologia. Por fim, esta também não é uma técnica, que significa - esta é habilidade, destreza ou ofício. Ou seja, técnica é um método específico para desempenhar alguma atividade, que pode ser artística, esportiva, profissional, científica, agrícola ou empresarial, por exemplo. Tecnologia, portanto, é um corpo de conhecimentos de técnicas, métodos e projetos que funcionam de maneiras determinadas e com efeitos determinados sobre certos tipos de eventos e atividades, ainda que não se possa sempre explicar as razões de seu desenvolvimento. 
Tecnologia não é apenas a high tech, que é a manifestação mais vistosa e sedutora da tecnologia. Ela está presente na história da humanidade, desde os seus primórdios e em vários setores da vida, em diferentes tipos de organização, e em graus de sofisticação variados.

Inovação, por sua vez, não é invenção e, menos ainda, pode-se confundir com "técnica" ou, ainda pior, com "tecnologia", o que é um erro crasso, embora comum. Segundo Figueiredo (2015),

\footnotetext{
a inovação, em sentido econômico, emerge apenas quando ocorre a primeira transação comercial envolvendo o novo produto, processo ou sistema, ou seja, é somente quando a invenção atinge a etapa de comercialização e inserção no mercado. Portanto, existe uma cadeia de eventos desde a invenção até a sua especificação ou aplicação como inovação, o que frequentemente envolve um caminho longo e arriscado" (FIGUEIREDO, 2015 p. 21, grifo acrescido).
}

Essas reflexões não se distaciam da conceituação conhecida sobre inovação originalmente proposto pelo famoso e Manual de Oslo, talvez o mais difundido documento sobre o tema, embora com foco nas atividades industriais. Segundo os vários esforços interpretativos realizados, uma situação de inovação representa a implementação de um produto novo (ou, pelo menos, um existente, mas significativamente aperfeiçoado), ou processo novo, ou método de comercialização ou novos métodos organizacionais nas praticas das firmas. O requerimento empírico mínimo, portanto, é que seja "novo", representando uma mudança em relação à situação anterior. A inovação, portanto, é o verdadeiro motor do capitalismo para promover o crescimento econômico. Haveria, segundo ele, na famosa expressão, uma lógica de "destruição criadora" que submete os ciclos econômicos. É afirmação que se baseia na percepção de que a estrutura econômica está constantemente sendo modificada em função da substituição de antigos produtos por novos produtos e de antigos hábitos de consumo por novas escolhas e comportamentos sociais, assim como novos processos organizacionais que igualmente criam valor (SCHUMPETER, 1957).

Segundo Nelson e Winter (2005), a lógica inovativa é naturalmente coordenada pela firma. Cabe à firma executar uma busca incessante pela inovação dentro de uma lógica evolucionária, pautando o ritmo de crescimento do mercado e, ao mesmo tempo, a 
dinâmica inovadora daquele segmento. Dessa forma, mercados mais concorrenciais tendem a possuir firmas mais inovadoras.

O papel central da firma no processo inovadora faz com que as empresas passem a observar a trajetória tecnológica, desenvolvidas por elas mesmas, como um ativo estratégico (ROSEMBERG, 2006). As trajetórias, ou opções tecnológicas exercidas pela firma no passado, são determinantes para a compreensão e o controle do processo de geração de inovação técnica. Assim, fatores como competência e capacidades, que naturalmente extrapolam a questão de capacidade técnica produtiva desdobra-se para aspectos também gerenciais (MAZZOLENI; OLIVEIRA, 2010). Tornando-se ativos, muitas vezes intangíveis e capazes de alavancar a possibilidade de geração de inovação (LALL, 1992; FIGUEIREDO, 2015).

A lógica da inovação exige um arcabouço de fatores operando e convergindo na direção da geração do produto ou processo inovativo. Portanto, deve-se pensar em inovação não exclusivamente como uma "caixa de competências técnicas", mas sim como um conjunto de técnicas, incluindo P\&D, que viabilizam a inovação em si. Assim, pode-se ter situações em que a firma possua um potencial inovador significativo, oriundo de uma forte capacidade de desenvolvimento de $P \& D$, mas é incapaz de viabilizar este potencial devido à pouca competência em outros departamentos que concluam o processp. Por fim, deve-se ter em mente que a firma possui um portfólio de competências, sendo que a inovação exige convergências de várias dessas competências em sua direção. Conclui-se, portanto, que a inovação não é exclusivamente de um resultado técnico, com foco em P\&D, mas sim um esforço convergente de vários departamentos afins.

\section{Metodologia}

A pesquisa organizou-se em duas etapas metodológicas consecutivas, contribuindo assim para um resultado final interpretativo rigorosamente assentado na literatura teórica e nos fatos empíricos. Tais etapas são brevemente descritas a seguir. A primeira etapa consistiu em realizar um esforço de vasculhar a literatura para escolher um produto biotecnológico que pudesse ser parcialmente equiparado ao caso do feijão transgênico. "Equiparar-se", aqui, significando, em particular, equivalência em dois aspectos principais: (a) a similaridade nos processos propriamente científicos, e (b) o "tempo potencial" para a a 
obtenção do resultado final (ambos deveriam ser pelo menos aproximados). Foi feita a escolha da abordagem analítica (neoinstitucionalismo histórico) e da arquitetura comparativa. Em seguida, foram levantados e pesquisados os casos do papaya transgênico (nos Estados Unidos) e do feijão transgênico (no Brasil), em suas especificidades empíricas.

A segunda etapa da pesquisa foi a mais demandante e aquela que pretendeu, de fato, oferecer "conhecimento novo". Foi feito um amplo levantamento documental, o qual somou-se à realização de entrevistas semi-dirigidas. Importante destacar que as entrevistas foram realizadas de forma anônima, pois os entrevistados relataram particularidades que não podem ser associados a nomes, ou por serem referidas a controvérsias ou, então, por descreverem situações produtoras de algum constrangimento institucional. Foram revisados todos os documentos (normas, textos, atas de reuniões e de audiências públicas, etc) relativos ao feijão transgênico na CTNBio (Comissão Técnica Nacional de Biossegurança), assim como ao tema dos transgênicos como um todo.

\section{Resultados e discussão}

\subsection{0 caso do papaya transgênico estadunidense}

Papaya ringspot virus (PRSV) é o vírus mais comum e prejudicial que infecta a planta do mamão papaya. O nome da doença causada por esse vírus é chamada comumente de "mancha anelar do papaya", pois um dos seus principais sintomas são as manchas escuras em forma de anel no fruto. As plantas infectadas com PRSV desenvolvem outros graves sintomas, como a perda de vigor, atrofiamento e a redução drástica na produção de frutos maduros. Consequentemente, em plantações onde a doença se instala os resultados econômicos são graves, praticamente inviabilizando a atividade. O PRSV é transmitido por um inseto e os hospedeiros do vírus são, além do próprio mamão papaya, as plantas da família cucurbitáceae (abóbora e outras espécies). O PRSV ocorre no mundo inteiro, mas especificamente nas regiões onde o mamão papaya é cultivado (GONSALVES, 1998) ${ }^{4}$.

\footnotetext{
${ }^{4}$ É importante destacar que essa seção foi elaborada a partir da bibliografia citada, mas também foi beneficiada com os esclarecimentos e informações prestadas pelo Dr. Denis Gonsalves, então ligado à Univerisdade do Havaí, através de mensagens pessoais trocadas via e-mail.
} 
A presença do PRSV foi relatado pela primeira vez em uma das ilhas do Havaí em 1940. Na década de 1950, o PRSV se alastrou e passou a afetar gravemente os cultivos de mamão dessa ilha. Sem conseguir controlar os efeitos da doença, a cadeia produtiva de papaya começou a se deslocar para outra ilha do arquipélago onde o vírus não existia. $\mathrm{Na}$ década de 1980, a uma distância de apenas 30 km das plantações principais, a ameaça de PRSV à indústria de mamão do Havaí tornou-se realidade. O governo do Havaí reconheceu esse grave problema e instruiu o seu Departamento de Agricultura (HDOA) para desenvolver um programa para evitar a disseminação do PRSV. Importante destacar que já havia um programa de pesquisa, iniciado em 1978, cujo objetivo era desenvolver estratégias de controle preventivo de PRSV no Havaí.

Dessa forma, despontaram os esforços científicos e as estratégias experimentais coordenadas por um fitopatologista havaiano do College of Tropical Agriculture (da Universidade do Havaí), o Dr. Denis Gonsalves. Primeiramente, se tentou, por meio de um método denominado "pré imunização" (como se fosse uma vacina) imunizar os mamoeiros. Esse método era utilizado com sucesso para controlar doenças viróticas semelhantes nos citros, no tabaco e na abobrinha (GONSALVES, 2014 ). Mas a pré-imunização conferiu pouca proteção ao mamão papaya. No entanto, essa linha de pesquisa não foi em vão, pois o gene da estirpe fraca do vírus foi utilizado na estratégia adotada a seguir: a transgenia. Também foi importante ter tentado a estratégia da pré imunização para que fosse possível compreender novos detalhes acerca das relações existentes no desenvolvimento da doença e decidir sobre o momento de desistir de uma dada abordagem. Nesse ponto não reside nenhuma surpresa, apenas revelando-se a operacionalidade do método científico: tentar as abordagens conhecidas (e seus métodos), aferindo os resultados em exercícios de laboratório e testes experimentais. Somente assim há avanço da ciência.

Dois artigos científicos publicados na década de 1980 foram decisivos para revolucionar as pesquisas que pretendiam desenvolver plantas transgênicas resistentes a vírus. No primeiro artigo, foi descrita a pesquisa que demonstrou o fenômeno pelo qual as plantas transgênicas contendo genes de vírus estão protegidas contra os efeitos prejudiciais dos mesmos (SANFORD; JOHNSTON, 1985). O segundo artigo descreveu um estudo que demonstrou que o tabaco transgênico, expressando o gene da proteína de revestimento do "vírus do mosaico do tabaco", estava protegido contra a infecção por esse mesmo vírus 
(POWELL-ABEL et al., 1986). Mais uma vez, demonstrou-se nesta etapa o avanço típico da ciência, ou seja, a construção cumulativa e sequencial, passo a passo, do conhecimento e, a partir desse avanço, em meados dos anos oitenta, Gonsalves e seus colaboradores iniciaram o desenvolvimento de resistência ao PRSV por meio de transgenia em mamão papaya.

A tentativa de obter plantas pré-imunizadas, antes referida, tinha sido consistentemente apoiada por meio de fundos do programa de pesquisa do USDA (United States Department of Agriculture) referente aos "problemas agrícolas da região do Pacífico". Esse programa também financiou a pesquisa para desenvolver o mamão papaya transgênico. A equipe de pesquisa foi formada pelos pesquisadores da Universidade do Havaí e da The Upjohn Company ${ }^{5}$, sob a coordenação de Gonsalves, também contando com a parceria da Universidade de Cornell ${ }^{6}$. Dessa forma, a equipe, contando com especialistas de várias áreas especificas, foi capaz de aprimorar técnicas e metodologias. Muitos artigos foram publicados e, o mais importante, a ciência mais uma vez avançou não exclusivamente no caso específico do mamão, mas desenvolveu novas técnicas e processos para as áreas de engenharia genética e de cultura de tecido vegetal.

Em 1991, ainda experimentalmente em casa de vegetação, uma determinada linhagem transgênica mostrou-se resistente ao PRSV. Em 1992, os testes em campo experimental confirmaram que o mamão papaya trasngênico era resistente à PRSV. Em seguida foram cruzados com cultivares de mamão papaya comerciais. Enquanto a pesquisa se desenvolvia, no início de 1992 foi detectado o PRSV e o HDOA imediatamente lançou um programa de erradicação de todas as plantas das áreas contaminadas, como uma estratégia preventiva. A medida, contudo, não foi aprovada pelos produtores de mamão papaya, o que gerou a reformulação do programa de controle pelo HDOA. Dessa vez, o objetivo era destruir apenas as plantas contaminadas. Em setembro daquele mesmo ano (1992), a chance de contenção do vírus deixou de existir, pois a incidência de PRSV aumentou dramaticamente e os agricultores, experimentando altas taxas de infecção, abandonaram

\footnotetext{
${ }^{5}$ The Upjohn Company foi uma indústria farmacêutica fundada em 1886, sediada na cidade de Kalamazoo, Michigan, tendo recebido o nome de seu fundador, um médico chamado William E. Upjohn. Em 1995, fundiu-se com outro gigante do setor, Pharmacia AB e em 2000 a nova firma completou um processo de fusão com a empresa Monsanto e Searle. Finalmente, em 2003, uniu-se à Pfizer, provavevelmente a indústria faramacêutica com maiores investimentos em pesquisa no mundo (WIKIPEDIA, 2016).

${ }^{6}$ Importante destacar que fazendo parte dessa equipe estava também John Sanford (da Universidade de Cornell), um dos responsáveis pelo desenvolvimento da "biobalística", entre outras técnicas no campo da engenharia genética.
} 
suas áreas de plantio. Esta decisão resultou em enormes reservatórios de vírus que seriam propagados pelos insetos transmissores. Igualmente dramático foi o impacto do PRSV sobre a cadeia produtiva do mamão papaya. Em pouco tempo, a produção de mamão papaya do Havaí caiu praticamente pela metade. Em 1992, por exemplo, aquele arquipélago contava com oito packing house ${ }^{7}$. Já em 1998, passou a contar apenas com três dessas estruturas (GONSALVES, 2014).

Para manter a produção de papaya, um plano ousado foi então proposto com previsão de financiamento pelo USDA: migrar a plantação de mamão papaya para outras áreas do Havaí, onde o PRSV não tinha sido detectado; erradicar completamente as plantas de mamão papaya e de cucurbitáceas (pois também são hospedeiras do vírus em questão) e, finalmente, estabelecer a moratória de um ano para novas plantações de papaya e de cucurbitáceas no local. No entanto, justamente nessa mesma época em que o referido plano estava sendo delineado, Gonsalves solicitou ao Biosafety Results of GMO Crops a autorização para realizar um grande ensaio de campo na área devastada pelo PRSV.

Tal solicitação foi aceita, sob diversas justificativas: o papaya transgênico já havia sido testado em campo experimental; este setor da economia havaiana precisava de ações ágeis para sobreviver, e o plano para mover a cadeia produtiva dificilmente teria êxito. Pesando contra a autorização para realizar o grande ensaio de campo existia a possibilidade de o pólen do mamão transgênico contaminar as plantações de mamão papaya não transgênico, resultando na possível venda de frutos comerciais com um transgênico ainda não aprovado pelas agências reguladoras, além da dificuldade de prevenção de furtos dos frutos geneticamente modificados e sua consequente disseminação. Ao fim e ao cabo, o teste de campo em área de produtor foi autorizado com a condição de serem obedecidas certas cautelas: (a) o campo deveria ser suficientemente isolado dos plantios convencionais; (b) todas as árvores abandonadas na área deveriam ser monitoradas, e (c) todos os frutos teriam que ser enterrados (GONSALVES, 2014; GONSALVES, 1998).

A aprovação para o grande ensaio de campo foi obtida no início de 1995 e o teste de campo foi montado em outubro de 1995, na propriedade de um agricultor que tinha deixado de cultivar mamão papaya por causa do PRSV. Os resultados do teste de campo demonstraram que as plantas transgênicas cresceram vigorosamente e seus frutos se

\footnotetext{
${ }^{7}$ Estruturas de beneficiamento, preparo prévio e empacotamento dos frutos seguirem para os distribuidores. 
formaram completamente. As plantas não transgênicas foram atrofiadas e poucas geraram frutos. Ou seja, o teste foi conclusivo para resistência das cultivares ao vírus e também confirmou as características dos cultivares comerciais de papaya (GONSALVES, 1998).

De acordo com a legislação nos Estados Unidos, cada produto transgênico não pode ser legalmente comercializado, a menos que seja formalmente autorizado pelos seguintes órgãos Department of Agriculture (USDA), Food and Drug Administration (FDA) e o Environmental Protection Agency (EPA). Como a cadeia econômica do mamão papaya no Havaí não contava com uma firma que possuísse a infraestrutura e a capacidade financeira para executar tal ação, foi preciso que a equipe de pesquisadores desempenhasse esse papel. Dessa forma, a partir de 1995 os cientistas atuaram para obter a aprovação regulatória desse produto transgênico no USDA (GONSALVES; GONSALVES, s/d; GONSALVES, 2014).

As licenças foram concedidas ao longo de 1997. No início do ano seguinte, o mamão papaya transgênico denominado Rainbow foi liberado para o plantio pelos agricultores e o direito à propriedade intelectual em questão foi cedido ao Comitê Administrativo do Papaya $(P A C)^{8}$, que é uma organização de produtores de mamão do Havaí (GONSALVES, 2014). 0 lançamento do mamão papaya transgênico ocorreu em maio de 1998 quando as sementes foram colocadas à disposição dos agricultores. No entanto, antes desse evento ocorrer, foi dada a oportunidade de os produtores terem acesso às sementes através de sua organização, o PAC. Dessa forma, a distribuição ocorreu de acordo com um plano pelo qual os agricultores que foram historicamente mais afetados pelo PRSV foram os primeiros a receber as sementes. Todos os agricultores, para receber os novos materiais, precisavam se registrar, assistir a uma sessão de capacitação e assinar um formulário de sublicenciamento (GONSALVES; GONSALVES, s/d).

Vencidas essas etapas, essa fruta transgênica e seus derivados passaram a ser vendidos para todos os Estados Unidos e em outros países, desde que fossem permitidas

\footnotetext{
${ }^{8}$ Esta comissão foi criada em 1971 sob a supervisão do USDA. O PAC ajuda proativamente os agricultores com relação à qualidade dos frutos, às normas, ao marketing e às outras questões para o agricultor produtor de papaya. Neste caso, esta incluída no trabalho de obter licenças para as tecnologias que foram usadas para desenvolver os papayas transgênicos, contratar com o Hawaii Agriculture Research Center para produzir as sementes e para o planejamento e distribuição de sementes aos agricultores. Sob o sistema PAC, todos os produtores do estado do Havaí que produzirem comercialmente mamões são obrigados a se tornarem membros.
} 
suas importações e comercializações. O Japão é um grande mercado para o mamão produzido no Havaí (desde a década de 1980) e o Canadá tem sido um mercado emergente. O papaya transgênico foi autorizado para venda no Canadá em 2003, o que permitiu uma significativa expansão do mercado. O caso do Japão representou um desafio maior. A viabilização do acesso a este mercado precisou novamente contar com esforços do pesquisadores. Eles precisaram conduzir esforços para avaliá-lo de acordo com as múltiplas e rigorosas exigências desse país. No Japão, foi autorizado apenas em 2011 (GONSALVES; GONSALVES, s/d).

Foi concebido um estudo, em tempo real, sobre a adoção do mamão papaya transgênico. A conclusão de que o agricultor havia adotado a semente foi definida apenas quando era verificado que o agricultor efetivamente plantou as sementes. Até setembro de 1999, 90\% dos agricultores tinha obtido sementes transgênicas e 76\% deles tinham plantado as sementes. A pesquisa também mostrou que os agricultores foram muito ágeis na implementação da tecnologia, pois entre aqueles que plantaram, $80 \%$ o fizeram nos primeiros três meses após o acesso à semente. Estudos mais recentes demonstram que a área plantada com papaya transgênico passou de 39\% (em 2000) para 83\% em 2009 (GONSALVES, 2014). Houve protestos contra o uso das sementes transgênicas de papaya por parte de grupos especiais de interesse. Em três ocasiões, pomares de mamão papaya transgênico foram cortados em parte esses grupos. Em um caso mais recente, o Estado e a cadeia produtiva de mamão papaya divulgaram recompensa de US\$ 30.000 para quem denunciasse os autores dos atentados. O fato é que se o público não tivesse aceito esse produto transgênico, os agricultores não iriam adotá-lo (GONSALVES; GONSALVES, s/d).

\subsection{0 caso do feijão transgênico brasileiro}

Atualmente, o feijão é plantado em quase todas as regiões do Brasil, não obstante a produção estar se concentrando nas regiões de maior modernização. Uma das mais importantes doenças que afeta a produção de feijão é chamada de "mosaico dourado do feijoeiro". As perdas causadas por essa doença variam de $40 \%$ a $100 \%$ da lavoura, causando grandes prejuízos aos agricultores. O causador da doença é um vírus denominado "vírus do mosaico-dourado do feijoero", cuja nomenclatura em língua inglesa é Bean golden mosaic 
vírus (BGMV). Seu vetor é um inseto denominado "mosca branca"9 (ARAGÃO; FARIA, 2010). A doença causada pelo BGMV é altamente infecciosa e persistente, isto é, quando o inseto adquire o vírus, irá transmití-lo por toda a vida. Apenas 3 moscas brancas por planta podem infectar a totalidade das plantas no campo (COLLI, 2014). São muitas as aplicações de inseticidas necessárias para controlar a incidência do inseto. No entanto, com o tempo há o desenvolvimento de resistência dessa praga ao inseticida.

O BGMV foi identificado pela primeira vez em 1961 em Campinas (SP). Em poucos anos, tornou-se um forte desafio para os pesquisadores, pois já causava graves problemas. Foram muitas as tentativas para a obtenção de plantas resistentes a esse vírus, por meio do melhoramento genético convencional ${ }^{10}$. Os resultados se mantiveram insatisfatórios, mesmo quando foram testados germoplasmas ${ }^{11}$ de várias regiões do mundo para tentar alcançar algum grau de resistência. Gastaram-se mais de duas décadas nessas tentativas científicas, mas o melhor obtido foram cultivares com resistências intermediárias, pois, apesar do acesso a uma grande quantidade de genótipos de feijão, o gene de resistência não se expressava por meio de melhoramento genético convencional. Diante de tamanho desafio, em 1989, o pesquisador Josias Corrêa de Faria, agrônomo, Ph.D. em Fitopatologia, pesquisador da Embrapa Arroz e Feijão (Goiânia), estabeleceu uma parceira de trabalho com seu colega Francisco José Lima Aragão, agrônomo, Doutor em Biologia Molecular, pesquisador da Embrapa Recursos Genéticos e Biotecnologia (Cenargen), em Brasília. O objetivo seria tentar, por meio da engenharia genética, desenvolver um feijão com resistência ao BGMV.

Em 1993, Aragão e sua equipe conseguiram demonstrar que era possível transformar geneticamente o feijão. Em 1995, foi obtida uma planta de feijão com sintomas brandos de "mosaico dourado do feijoeiro" e que também apresentava sintomas tardios da doença. Portanto, essa planta transgênica não era totalmente imune ao BGMV, mas já era mais vantajosa do que a planta não modificada. Isso foi um passo importante em termos de conhecimento científico acumulado e novas práticas laboratoriais. No entanto, o objetivo

\footnotetext{
9 A recomendação agronômica usual para evitar a incidência desse vírus tem sido a implementação do vazio sanitário. Trata-se de uma técnica que consiste em determinar um período de ausência completa de plantas vivas de feijão e de qualquer planta (inclusive as daninhas) que possam ser hospedeiras da mosca branca na área onde se deseja plantar feijão.

${ }^{10}$ Cruzamento sexual entre plantas e seleção dos cultivares formados de maior sucesso.

${ }^{11}$ Materiais genéticos de uma dada espécie disponível para melhoramento genético.
} 
perseguido pelos pesquisadores sempre foi o da imunidade total e, assim, a pesquisa prosseguiu. Outra estratégia foi adotada por Aragão e seus colaboradores, diferente daquela utilizada no caso do mamão papaya. Assim, em 1999, foi obtida uma planta de feijão transgênica com imunidade total ao BGMV em laboratório e na casa de vegetação. Foi denominada "Evento Feijoeiro Embrapa M1-4".

Ao passo em que estava aguardando a permissão oficial para testar o "Evento Feijoeiro Embrapa M1-4" em campo experimental nas instalações do Cenargen, Aragão desenvolvia uma nova forma de resistência ao vírus, por meio de outro método de engenharia genética ${ }^{12}$, completamente diferente daqueles utilizados no desenvolvimento do papaya transgênico e do "Evento Feijoeiro Embrapa M1 - 4". A esse feijão novo com resistência ao vírus foi dado o nome de "Evento Feijoeiro Embrapa 5.1" (em 2004). Novamente, o feijão apresentou total resistência ao BGMV, quando testado em laboratório e casa de vegetação. É importante fazer uma observação: o vírus do mamão papaya é do tipo "vírus de RNA" e o vírus do feijão é do tipo "vírus de DNA". Quando foi iniciado o desenvolvimento do papaya transgênico, a estratégia de transgenia para "vírus de RNA" já era conhecida mundialmente. No entanto, a estratégia de transgenia para "vírus de DNA" não existia. A primeira vez que foi demonstrado que era possível fazer transgenia com "vírus de DNA" ocorreu a partir da pesquisa com o feijão, gerando artigos científicos em revistas internacionais de reconhecido prestígio e, por isso, foi escolhido como modelo para aprimorar as regras de biossegurança em todo o mundo. Essa estratégia passou a ser utilizada em outros países. Estão sendo desenvolvidos milho (na África do Sul), tomate (em Cuba) e mandioca (em Estados Unidos) com resistência a vírus.

A legislação para autorização da etapa de pesquisa em campo experimental nas instalações do Cenargen exigia que fosse solicitado um RET (Registro Especial Temporário) ao Mapa (Ministerio da Agricultura, Pecuária e Abstecimento). O pedido foi feito em 2001 mas, nessa época, havia uma ambiguidade na legislação brasileira entre o que seria transgênico e o que é "agrotóxico". O feijão transgênico foi espantosamente classificado como agrotóxico extremamente tóxico. Por outro lado, as regras ainda eram profundamente confusas entre as exigências do Mapa e do Ministério do Meio Ambiente (MMA). Provavelmente movido por essas ambiguidades, em 2001, o Juíz Federal da 14ạ Vara do

\footnotetext{
${ }^{12}$ Estratégia do RNA interferente para silenciar o REP do vírus, assim o vírus não se replica.
} 
Distrito Federal deferiu uma liminar, determinando que fossem suspensas todas as autorizações para o cultivo de sementes geneticamente modificadas, nos quais os interessados não detenham o Registro Especial Temporário (RET) e determinou que não fossem expedidas novas autorizações sem a observação desse requisito.

Além do RET, concedido pelo Mapa, uma longa lista de outros requerimentos burocráticos previstos em leis e demais normas eram exigidas para a realização da pesquisa: ATP (Avaliação Toxicológica Preliminar), concedida pela Anvisa; AAP (Avaliação Ambiental Preliminar), concedida pelo Ibama; Loap (Licença para Operação de Áreas de Pesquisa), concedida pelo Ibama (Instituto Brasileiro do Meio Ambiente e dos Recursos Naturais Renováveis); Atec (Autorização para Experimentação no Campo) concedida pelo Mapa; o CQB (Certificado de Qualidade de Biossegurança), concedido pela CTNBio (Comissão Técnica Nacional de Biossegurança) e finalmente, o Parecer Técnico também concedido pela CTNBio. Os pesquisadores, apropriadamente, apelidaram essa lista de exigências de "caminho do inferno".

Em março de 2004, houve, nas instalações do Cenargen, localizado no campus central da Embrapa, uma cerimônia de entrega do Loap pelo Ibama, autorizando o teste com feijão transgênico em campo experimental (AGÊNCIA BRASIL, 2004). Dessa forma, foi iniciado o experimento de campo do "Evento Fejoeiro Embrapa MI-4". Mas apenas 60\% das plantas apresentaram resistência em campo experimental. No entanto, como antes comentado, a partir de 2000 a equipe de pesquisadores já havia iniciado uma nova pesquisa para desenvolver outro feijão com a mesma resistência, mas seguindo uma outra estratégia biotecnológica. Portanto, nesse mesmo ano, obteu-se o "Evento Feijoeiro Embrapa 5.1", cuja resistência ao vírus do mosaico dourado foi verificada em $100 \%$ das plantas, quando testadas em campos experimentais.

Em 2005, foi sancionada a nova Lei de Biossegurança e, em seguida, a Resolução Normativa da CTNBio no 5 (12 de março de 2008) organizou, sob uma listagem de perguntas, os requerimentos necessários para dar entrada com um processo de pedido de comercialização de transgênicos. Para respondê-las, Aragão e seus colaboradores montaram uma grande equipe multidisciplinar. Dessa forma, a equipe passou a contar com 62 pesquisadores de seis unidades da Embrapa e quatro universidades públicas. Em dezembro de 2010, os representantes legais da Embrapa apresentaram o "Requerimento de liberação 
comercial do feijoeiro geneticamente modificado resistente ao vírus do mosaico dourado do feijoeiro" (mais precisamente o Evento Feijoeiro Embrapa 5.1 ) à CTNBio. O pedido veio acompanhado de um longo, complexo e detalhado documento sobre o desenvolvimento do feijão transgênico ${ }^{13}$

Durante o ano de 2011, a "Campanha nacional por um Brasil livre de transgênicos"14 investiu esforços contrários à autorização comercial do feijão transgênico da Embrapa, defendendo o argumento de que a alternativa para os agricultores seriam as sementes crioulas (uma das bandeiras dos militantes da agroecologia no Brasil), segundo a AS-PTA (2016). Em julho de 2011, o Conselho Nacional de Segurança Alimentar (Consea), abrigado na Presidência da República, sugeriu formalmente, a "proibição da liberação comercial do feijão transgênico" da Embrapa à Presidente da República (RBA, 2011). Apesar de o Consea não ter poder de veto, essa postura do Consea chamou a atenção, principalmente pelo fato de se tratar de um produto básico de segurança alimentar, além de evitar inseticida, sendo mais saudável que seu similar convencional. Entre as entidades da sociedade civil representadas no Consea, estão, por exemplo, a Articulação dos Povos Indígenas do Nordeste, Minas Gerais e Espírito Santo; Articulação Nacional de Agroecologia; Rede Evangélica Nacional de Ação Social; Agentes de Pastoral Negros; Rede de Mulheres Negras para a Segurança Alimentar e Nutricional; Articulação dos Povos Indígenas da Região Sul; Associação em Áreas de Assentamento no Estado do Maranhão, entre outros. Não foi possível encontrar justificativa documentada que comprovaria a relevância e a legitimidade dessas organizações, tornando-as candidatas naturais para tomar assento no Consea. O que se sabe é que muitas dessas ONGs fazem parte da "Campanha por um Brasil livre de transgênicos".

Antes de o parecer técnico sobre o feijão transgênico ser votado na CTNBio, foi realizada uma Audiência Pública, quando vários representantes de ONGs e até um religioso e também conselheiro do Consea, pediram o veto à autorização do uso comercial do feijão

\footnotetext{
${ }^{13}$ Proposta de Liberação Comercial de Feijoeiro Geneticamente Modificado Resistente ao Mosaico Dourado Evento Embrapa 5.1 (EMB - PV 051-1) encaminhado à CTNBio em dezembro de 2010 - documento obtido em mãos.

${ }^{14}$ Essa Campanha foi lançada em 1999 por algumas organizações não governamentais ONGs. Existe até hoje e, desde aquele ano, produz um boletim divulgado amplamente pela internet tentando demonstrar os motivos pelos quais os transgênicos não são uma solução para a agricultura. A solução é a "agroecologia". Essa campanha foi fortemente apoiada por ONGs internacionais em seu início, mas nos últimos anos passou a ter apoio do Governo brasileiro.
} 
(FERNANDES, 2011). No entanto, em 15 de setembro de 2011, a CTNBio concluiu que o feijão transgênico era tão seguro quanto seus equivalentes convencionais e que o pedido de liberação comercial atendeu às normas e as legislações vigentes que visam garantir a biossegurança do meio ambiente, da agricultura, da saúde humana e da saúde animal. Portanto, aprovou sua liberação para uso comercial (COLLI, 2014). O fato foi amplamente notíciado pela Embrapa e repercutiu na mídia nacional (GLOBO RURAL, 2011). Os produtores de feijão, quando informados sobre o novo produto passaram a procurar insistentemente os pesquisadores da Embrapa para ter acesso à nova variedade.

O que não significou que o feijão, contudo, foi disponibilizado imediatamente para os agricultores pela Embrapa, a detentora da tecnologia. Em 2014, a Embrapa postergou a disponibilização do feijão transgênico. A justificativa era que seria preciso desenvolver desenvolver um feijão resistente a um outro vírus por meio do melhoramento genético convencional, para ser depois cruzado com o feijão transgênico ${ }^{15}$. Essa decisão foi amplamente comemorada pelos grupos contrários aos transgênicos (JC NOTÍCIAS, 2004).

\subsection{Comparação entre os dois casos}

O uso da metodologia comparativa permitiu interpretar essa diferença e "estranhar" o caso brasileiro, pois revelou as evidências que estavam sombreadas por aquilo que nos é "conhecido". O exercício comparativo permite superar as resistências, (conscientes ou inconscientes) que temos da realidade que nos é conhecida e estar aberto para compreender o fenômeno com o menor nível de erro possível. Essa superação é facilitada quando um determinado fenômeno social, político ou econômico pode ser analisado em termos de variáveis (AZARIAN, 2011, p. 117; TAYLOR, 2000; RAGIN, 1994). Nesse exercício de comparação, apresenta-se abaixo o quadro que relaciona as etapas do percurso institucional pelos quais os dois produtos (papaya e feijão transgênicos) passaram (Quadro 1).

\footnotetext{
${ }^{15}$ Segundo Nota Técnica da Embrapa sobre o carlavírus -conteudoweb. 
Quadro 1: Percurso comparativo dos OGMs analisados nos Estados Unidos e no Brasil das etapas científicas à adoção

\begin{tabular}{|l|c|l|}
\hline \multicolumn{1}{|c|}{ Etapas } & Papaya GM (EUA) & \multicolumn{1}{|c|}{ Feijão GM (Brasil) } \\
\hline Início da Pesquisa & Final dos anos de 1980 & Início dos anos de 1990 \\
\hline $\begin{array}{l}\text { Obtenção da linhagem resistente } \\
\text { (laboratório e casa de vegetação) }\end{array}$ & 1991 & 2004 \\
\hline Pesquisa em campo experimental & 1992 & 2006 \\
\hline Ensaio em área de produtor & 1995 & $\begin{array}{l}\text { Somente é permitido, } \\
\text { quando há CQB }\end{array}$ \\
\hline Solicitação para uso comercial & 1995 & 2010 \\
\hline $\begin{array}{l}\text { Licenças concedidas para } \\
\text { comercialização }\end{array}$ & 1997 & 2011 \\
\hline $\begin{array}{l}\text { Disponibilização do produto para os } \\
\text { agricultores }\end{array}$ & 1998 & Não foi disponibilizado \\
\hline Análise sobre a adoção do feijão & 1999 & $\begin{array}{l}\text { Não foi realizada, porque } \\
\text { não foi disponibilizado }\end{array}$ \\
\hline
\end{tabular}

Fonte: Elaborado pelos autores, com base em Gonsalves (1998; 2014) e Aragão e Faria (2010).

Como é possível verificar na descrição dos dois casos, em termos de desenvolvimento de tecnologias para os produtores, os dois países (Brasil e Estados Unidos) foram capazes de desenvolver plantas geneticamente modificadas resistentes a vírus. Foram experimentos científicos semelhantes sob alguns ângulos. Um deles é que o tempo da experimentação (em anos, nos dois casos) para realizar testes de laboratório e de casa de vegetação é muito parecido. Da mesma forma, o que poderia ser intitulado de "complexidade científica" envolvida nos dois casos também é similar, reforçando a possibilidade analítica. No entanto, há uma abissal diferença a ser destacada: O mamão papaya transgênico dos Estados Unidos foi desenvolvido e disponibilizado para os agricultores com impressionante rapidez. Eles adotaram e, portanto, ocorreu a inovação tecnológica. O feijão transgênico do Brasil, por sua vez, foi desenvolvido e aprovado para uso comercial. Também houve comemoração dessa conquista pela Embrapa, repercutindo na mídia, mas não foi disponibilizado para os agricultores.

Em 1991, o papaya transgênico mostrou-se resistente ao vírus. Sua avaliação em 
campo aberto ocorreu no ano seguinte. No caso do feijão, sua resistência foi observada em 2004, mas dois anos se passaram antes de realizada sua avaliação em campo aberto (nas áreas experimentais da Embrapa). Em 1995, o papaya transgênico foi avaliado em área de produtor. Ou seja, quatro anos após seu desenvolvimento. No Brasil, somente é permitida a avaliação em área de produtor se houver CQB (Certificado de Qualidade de Biossegurança). Essa exigência traz vantagens para as empresas privadas que facilmente podem arrendar terras de produtores e solicitar o CQB à CTNBio. A Embrapa não tem esta facilidade para realizar esses testes. O que se percebe, na comparação, é que o papaya transgênico foi desenvolvido em 1991 e disponibilizado para os agricultores em 1998 - sete anos, portanto, entre esses dois momentos. O feijão transgênico foi desenvolvido em 2004 mas até o momento não foi disponibilizado para uso comercial e possível adoção pelos agricultores. Ou seja, 14 anos entre esses dois momentos.

As licenças para o mamão papaya transgênico foram concedidas em 1997 e quase imediatamente, já no ano seguinte, as sementes foram disponibilizadas para os agricultores havaianos. Já para o feijão GM, a autorização da CTNBio foi concedida em 2011, mas as sementes ainda não foram disponibilizadas para os produtores. Chama também a atenção o fato de o mamão papaya transgênico ter sua adoção por parte dos agricultores avaliada em tempo real. Isso demonstra uma noção clara e objetiva por parte das instituições de pesquisa dos Estados Unidos envolvidas no desenvolvimento desse importante produto, de que a inovação tecnológica não se conclui no desenvolvimento e na disponibilização de um dado produto. A inovação, portanto, somente se concretiza quando o produto se transmuta em mercadoria e é adotado. Ou seja, quando ocorre a sua aceitação pela cadeia agroalimentar.

O governo do Havaí reconheceu o problema da doença nos plantios de mamão papaya. E o Departamento de Agricultura do Havaí já desenvolvia estratégias de controle da doença. Foi realizada imediata parceria entre as Universidades do Havaí e Cornell e a empresa privada The Upjohn Company. Para realizar a pesquisa foram usados fundos do USDA. A autorização para ensaio em campo aberto, inclusive em área de agricultor, foi solicitada à Biosafety Results of GMO Crops. No caso do feijão transgênico, para realizar a fase da pesquisa após a fase de laboratório, era necessário obter o RET. O feijão transgênico, no inicio, foi considerado um agrotóxico. Como um juíz deferiu liminar suspendendo todos 
os transgênicos com características de agrotóxicos, determinou que não fossem emitidos RETs. Além do RET eram necessários outros seis requerimentos ( $A T P, A A P$, Loap, Atec, CQB e Parecer Técnico) para conseguir realizar essa etapa. Esses requerimentos eram solicitados na Anvisa, Ibama, Mapa e CTNBio. A partir da Nova Lei de Biossegurança (2005) e, mais precisamente, a partir de uma Resolução Normativa (2008) da CTNBio, foi necessário montar uma equipe multidisciplinar contando com outras quatro unidades da Embrapa e quatro universidades para responder aos requerimentos da CTNBio. Antes da aprovação do feijão transgênico pela CTNBio, a "Campanha por um Brasil livre de transgênicos" e o Consea se posicionaram contrariamente ao feijão transgênico e a Embrapa vem postergando sua disponibilização para os agricultores.

\section{Considerações finais}

Embora o mamão papaya transgênico tenha sido autorizado pelos órgãos competentes dos Estados Unidos e vem sendo comercializado há 14 anos, é um caso emblemático, pois fornece um argumento convincente do impacto de uma inovação tecnológica que praticamente salvou a cadeia produtiva do setor; envolveu cientistas do setor público que não receberam apoio financeiro de empresas privadas. Além disso, demonstra a necessidade da agilidade, quando uma circunstância emergencial exige um forte esforço de pesquisa. É um sucesso de inovação tecnológica agropecuária. O que se percebe, nesse caso, é que o Estado estava alerta para questões de fitossanidade que atingiam a economia do setor. Se os esforços de pesquisa tivessem sido iniciados somente quando o vírus foi detectado, em 1992, muito provavelmente, a indústria do mamão no Havaí teria desaparecido por volta do ano em que esse produto tornava-se disponível comercialmente.

O caso do feijão transgênico é também emblemático. Mas como um exemplo de que o desenvolvimento de tecnologia não é sinônimo de inovação tecnológica. Apesar de ser um produto tão sofisticado e necessário quanto o mamão papaya transgênico, de ter sido aprovado por uma Comissão de especialistas (CTNBio), de ter sido comemorado amplamente esse avanço científico, de os agricultores precisarem desse produto, de a produção de feijão convencional estar sofrendo muitas perdas e tendo uso exarcebado de 
inseticidas, não foi disponilizado para a sociedade brasileira.

Os avanços do conhecimento científico se aceleram, uma avalanche de novas ideias, concepções, paradigmas se reestruturam, perspectivas se alargam e se reformulam continuamente. A interface entre ciência e tecnologia cada vez mais se enlaça. Sociedade e Estado ficam embebidos em uma grande teia de mudanças tecnológicas, os impactos são gerais em todos os segmentos sociais. É desnecessário enumerar as mudanças provocadas pelas Tecnologias de Informação e Comunicação (TICS) que, entre outras mudanças, afetam a vida cotidiana. São inúmeras as implicações econômicas, éticas e nas relações interpessoais, demandando normas e regulações por parte do Estado. Como exemplo, a repercussão da Internet e dos smart phones e suas consequências ("Uberização" entre outros) para o trabalho e o comportamento humano. As instituições sociais são impactadas pela mudança, surgem novas abordagens, é a sociedade pós-industrial ou pós-material e os valores a ela associados (INGLEHART; WELZEL, 2009).

No domínio biológico estão provavelmente os mais importantes desafios quanto a regulação de procedimentos e dos objetivos da mudança tecnológica. As mudanças decorrentes do aumento do conhecimento sobre a estrutura da vida em plantas e animais trazem preocupações quanto às repercussões na saúde humana e na natureza em geral (SCHWAB, 2017). Há um temor que plantas modificadas possam produzir impactos nocivos na saúde e no meio ambiente, sendo referidas como os "alimentos Frankenstein". Esse temor tem produzido reações organizadas principalmente por meio da ação de ONGs, segmentos do meio artístico-intelectual com repercussões na mídia e nas redes sociais e até de certos grupos com apelos místicos à "mãe natureza". Caracterizam uma reação conservadora que utiliza argumentos pseudocientíficos com hostilidade ao novo no campo das ciências biológicas embora, paradoxalmente, compartilhem de todos os avanços tecnológicos da comunicação digital. As reações às inovações no meio biológico possuem certa semelhança ao ludismo do Século XIX, inclusive marcadas pela invasão e depredação de laboratórios e campos experimentais de plantas. Cresce a reação ao uso de remédios inovadores e até às vacinas (o que tem aumentado o caso de doenças superadas há muitas décadas) juntamente ao retorno ao uso de remédios tradicionais como plantas com poderes curativos, chás, homeopatias, cromoterapias, etc. , difundidos em redes sociais e baseados em falsos argumentos científicos. Um apelo confuso de retorno à natureza que associa a 
inovação tecnológica nas ciências biológicas à degradação do meio ambiente e da vida no planeta.

Por que o desenvolvimento da inovação científica no caso do feijão transgênico não se transformou em inovação tecnológica? Ou, o que interferiu, no caso brasileiro, para impedir ou retardar uma inovação tecnológica em um campo tão importante para a economia do país? Os parâmetros para medir desenvolvimento e condições de vida de um país fazem sentido apenas em uma perspectiva comparativa. Neste artigo a referência de comparação foi uma inovação biológica de planta nos Estados Unidos. Acemoglu e Robinson (2013) consideram a perspectiva institucionalista, partindo da premissa de North (1990; 2005), ou seja, nas instituições está a chave da compreensão das condições de vida nas nações, não necessariamente do desenvolvimento (ou do crescimento econômico), mas das suas diferenças, já que o conceito de desenvolvimento possui conotação valorativa, ver por exemplo Sen (2000). No contexto do feijão transgênico brasileiro cabe indagar qual circunstância institucional impediu a inovação tecnológica. Giddens (1998) colocou o dilema da abordagem institucionalista: é a "boa instituição" que produz a "boa sociedade" ou é o contrário?

No Brasil ainda existem resistências ao aumento de produtividade e ao sucesso econômico na agropecuária descortinado pela crítica negativa de ONGs e meios acadêmicos ao desempenho do chamado de forma simplificada e pejorativa em certos meios de "agronegócio". O agronegócio tem sido propagado como inimigo do meio ambiente e da vida saudável, produto do capitalismo selvagem. Setores acadêmicos associados ao modismo "naturalista" de ONGs propagam intensamente, nas redes sociais, essa visão, estabelecendo um ambiente institucional contrário ao ambiente de inovação tecnológica em relação a transgênicos, principalmente quando dependente do Estado e de suas regulações. Esse conjunto de crenças e normas de conduta prescritas constituem uma estrutura institucionalizada no sentido que North (1990) sugere, refletindo nas regulações do Estado. A Embrapa enquanto entidade estatal fica mais sujeita ao controle e pressões de movimentos institucionalizados. No caso em questão, o Estado age como inibidor, já que a inovação tecnológica, regra geral, é associada à circulação de ideias (cada vez mais baseadas na ciência) e de mercadorias, ou seja, a um ambiente institucional que favoreça em certa medida ao valor atribuído à liberdade de iniciativas econômicas (MUSACCHIO; LAZZARINI, 2014). 


\section{Referências}

ACEMOGLU, D.; ROBINSON, J. Why nations fail: the origins of power, prosperity and poverty. New York: Crown Publishing, 2013.

AGÊNCIA BRASIL. Pesquisa da Embrapa com feijão transgênico recebe "passe livre". 2004. Disponível em: <http://memoria.ebc.com.br/agenciabrasil/noticia/2004-03-12/pesquisa-daembrapa-com-feijao-transgenico-recebe-passe-livre>. Acesso em: 19 out. 2016.

ARAGÃO, F. J. L.; DE FARIA, J. C. Proposta de Liberação Comercial de Feijoeiro Geneticamente Modificado Resistente ao Mosaico Dourado - Evento Embrapa 5.1 (BEM-PV 051-1), Embrapa. Documento enviado para a CTNBio, 2010.

AS-PTA. Boletim 546 - 15 de julho de 2011. Disponível em:

<http://aspta.org.br/campanha/boletim-546-15-de-julho-de-2011>. Acesso em: 21 out. 2016.

AZARIAN, R. Potentials and limitations of comparative methods in Social Sciences. International Journal of Humanities and Social Sciences (4), 2011. p. 113-125.

COLLI, Walter. EMBRAPA: uma decisão que se impõe. 2014. Disponível em: <http://www.jornaldaciencia.org.br/embrapa-uma-decisao-que-se-impoe>. Acesso em: 24 out. 2016.

FERNANDES, Gabriel B. Contribuições da AS-PTA à audiência pública referente ao feijoeiro geneticamente modificado - processo CTNBio 01200.005161/2010-86. 2011. Disponível em: <http://ctnbio.mcti.gov.br/documents/566529/673004/Manifesta\%C3\%A7\%C3\%A3o+Gabri el+Fernandes.pdf/08db4d02-84a7-4c0d-a011-b4e0ce809c3f?version=1.0>. Acesso em: 7 out. 2016.

FIGUEIREDO, P. N. Gestão da inovação: conceitos, métricas e experiências de empresas no Brasil. 2. ed. Rio de Janeiro: LTC, 2015.

GIDDENS, Anthony. Política, sociologia e teoria social. São Paulo: UNESP, 1998.

GLOBO RURAL. Feijão transgênico desenvolvido pela Embrapa é aprovado no Brasil. Disponível em: <http://revistagloborural.globo.com/Revista/Common/0,,EMI26534518078,00-FEIJAO+TRANSGENICO+DESENVOLVIDO+PELA+EMBRAPA+E+APROVADO+NO+ BRASIL.html>. 2011. Acesso: 24 out. 2016.

GONSALVES, D. Control of Papaya Ringspot Virus in Papaya: A case Study. Ann. Rev. Phytoputhul, v. 36, p. 415-437, 1998.

Hawaii's Transgenic Papaya Story 1978-2012: A personal Account. Metadata of the chapter that will be visualized online. Copyrigh Year 2014 (Enviado por e-mail para a autora da tese pelo autor). 
GONSALVES, C. V; GONSALVES, D. The Hawaii Papaya Story. (Enviado por email para a autora da tese pelo segundo autor).

INGLEHART, R.; WELZEL, C. Modernização, mudança cultural e democracia: a sequência do desenvolvimento humano. São Paulo: Francis, 2009.

JC NOTÍCIAS. Ministro da C\&T anuncia acesso gratuito ao catálogo do Cbers. 2004. Disponível em: <http://jcnoticias.jornaldaciencia.org.br/ministro-da-ct-anuncia-acessogratuito-ao-catalogo-do-cbers>. Acesso em: 9 nov. 2016.

LALL, S., Las Capacidades tecnológicas. In: Salomon, S. S. (Org.). Una búsqueda incierta: Ciência, tecnología y desarrollo. México: Ediciones FCE, 1992.

MAZZOLENI, E. M.; OLIVEIRA, L. G. Inovação Tecnológica na Agricultura Orgânica: estudo de caso da certificação do processamento pós-colheita. RESR, Brasília, 48, p. 567-586, 2010.

MUSACCHIO, A; LAZZARINI, S. G. Reinventando o capitalismo de Estado: O Leviatã nos negócios: Brasil e outros países. São Paulo: Portfolio-Penguin, 2014.

NELSON, R.; WINTER, S. G. Uma teoria evolucionária da mudança econômica. Campinas: Unicamp, 2005.

NORTH, D. C. Institutions, Institutional change and Economic Performance. New York: Cambridge University Press, 1990.

Press, 2005. Understanding the Process of Economic Change. Princeton: Princeton University

POWELL-ABEL, P. R. S. et al. Delay of disease developmentin transgenic plants that express the tobacco mosaic virus coat protein gene. In: Science 4751, n. 43, p. 783, 1986.

RAGIN, C. Constructing social research. Part I: "Elements of Social Research", p. 5-76. Thousand Oaks: Pine Forge Press, 1994.

RBA. Rede Brasil Atual. Poder de comissão que libera transgênicos é questionado. Acesso em: $<$ http://www.redebrasilatual.com.br/cidadania/2011/10/poder-de-comissao-que-liberatransgenicos-e-questionado>. 2011. Acesso em: 28 set. 2016.

ROSEMBERG, N. O aprendizado pelo uso. In: ROSEMBERG, N. (Org.). Por dentro da caixa preta: tecnologia e economia. Campinas: Unicamp, 2006.

SANFORD, J.C.; JOHNSTON. The Concep of Parasite-Derived Resistance - Deriving resistance genes from the parasite's own genome. In: Journal of Theoretical Biology, 113, p. 395-405, 1985. 
SCHUMPETER, J. A. The Theory of Economic Development. Cambridge: Harvard University Press, 1957.

SCHWAB, K. A quarta revolução industrial. São Paulo: Edipro, 2017.

SEN, Amartya. Desenvolvimento como Liberdade. São Paulo: Companhia das Letras, 2000.

TAYLOR, C. Coração, História, Verdade. In: TAYLOR, C (Org.). Argumentos filosóficos. São Paulo: Loyola, 2000.

WIKIPEDIA. Upjohn. Disponível em: <https://en.wikipedia.org/wiki/Upjohn>. Acesso em: 24 out. 2016.

WOOTTON, D. 2015. The Invention of Science. A New History of the Science Revolution. Nova York: Harper, 2015. 